\title{
The impact of sagittal balance on clinical results after posterior interbody fusion for patients with degenerative spondylolisthesis: A Pilot study
}

\author{
Mi Kyung Kim ${ }^{1,2}$, Sun-Ho Lee ${ }^{1 *}$, Eun-Sang Kim, Whan Eoh ${ }^{1}$, Sung-Soo Chung ${ }^{3}$ and Chong-Suh Lee ${ }^{3}$
}

\begin{abstract}
Background: Comparatively little is known about the relation between the sagittal vertical axis and clinical outcome in cases of degenerative lumbar spondylolisthesis. The objective of this study was to determine whether lumbar sagittal balance affects clinical outcomes after posterior interbody fusion. This series suggests that consideration of sagittal balance during posterior interbody fusion for degenerative spondylolisthesis can yield high levels of patient satisfaction and restore spinal balance
\end{abstract}

Methods: A retrospective study of clinical outcomes and a radiological review was performed on 18 patients with one or two level degenerative spondylolisthesis. Patients were divided into two groups: the patients without improvement in pelvic tilt, postoperatively (Group $A ; n=10$ ) and the patients with improvement in pelvic tilt postoperatively (Group B; $n=8$ ). Pre- and postoperative clinical outcome surveys were administered to determine Visual Analogue Pain Scores (VAS) and Oswestry disability index (ODI). In addition, we evaluated full spine radiographic films for pelvic tilt (PT), sacral slope (SS), pelvic incidence (PI), thoracic kyphosis (TK), lumbar lordosis (LL), sacrofemoral distance (SFD), and sacro C7 plumb line distance (SC7D)

Results: All 18 patients underwent surgery principally for the relief of radicular leg pain and back pain. In groups A and B, mean preoperative VAS were 6.85 and 6.81, respectively, and these improved to 3.20 and 1.63 at last followup. Mean preoperative ODI were 43.2 and 50.4, respectively, and these improved to 23.6 and 18.9 at last follow-up. In spinopelvic parameters, no significant difference was found between preoperative and follow up variables except PT in Group A. However, significant difference was found between the preoperative and follows up values of PT, SS, TK, LL, and SFD/SC7D in Group B. Between parameters of group A and B, there is borderline significance on preoperative PT, preoperative LL and last follow up SS.

Correlation analysis revealed the VAS improvements in Group A were significantly related to postoperative lumbar lordosis (Pearson's coefficient $=-0.829 ; \mathrm{p}=0.003$ ). Similarly, ODI improvements were also associated with postoperative lumbar lordosis (Pearson's coefficient $=-0.700 ; p=0.024$ ). However, in Group B, VAS and ODI improvements were not found to be related to postoperative lumbar lordosis and to spinopelvic parameters.

Conclusion: In the current series, patients improving PT after fusion were found to achieve good clinical outcomes in degenerative spondylolisthesis. Overall, our findings show that it is important to quantify sagittal spinopelvic parameters and promote sagittal balance when performing lumbar fusion for degenerative spondylolisthesis.

\footnotetext{
* Correspondence: sobotta72@hotmail.com

'Department of Neurosurgery, Spine center, Samsung Medical Center, Sungkyunkwan University, School of Medicine, Seoul, 135-710, Republic of Korea

Full list of author information is available at the end of the article
}

\section{() Biomed Central}

(C) 2011 Kim et al; licensee BioMed Central Ltd. This is an Open Access article distributed under the terms of the Creative Commons Attribution License (http://creativecommons.org/licenses/by/2.0), which permits unrestricted use, distribution, and reproduction in any medium, provided the original work is properly cited. 


\section{Background}

The clinical outcomes of spinal fusion in degenerative spondylolisthesis are influenced by a variety of pathophysiologic factors, such as, the recurrence of spinal canal stenosis, instability, lumbar kyphosis, nonunion, and the disturbance of adjacent segments [1,2]. Although satisfactory clinical outcomes have been reported for a variety of surgical techniques, the optimal management of degenerative spondylolisthesis remains controversial. Recently, laboratory and clinical evidence has indicated that if fusion surgery is undertaken, improved short- and long-term outcomes can be achieved by correcting any sagittal deformity present [3-5].

Some studies have attempted to correlate spinopelvic parameters with health related quality of life (HRQOL) or pain measures in order to provide some insight during surgical planning for isthmic spondylolisthesis [6,7]. These studies identified key radiographic parameters that are correlated with patient pain and disability, and found that pelvic tilt (PT) is related to HRQOL [8]. However, these studies were not without limitations, and evidence supporting this relationship remains limited and it has not been determined whether sagittal vertical axis influences clinical outcomes in degenerative spondylolisthesis [9-11].

The purpose of this study was to explore the relationships between pelvic tilt and other spinopelvic parameters and with clinical outcomes after spinal fusion for degenerative spondylolisthesis. In addition, we attempted to determine whether specific critical values of spinopelvic parameters can predict poor HRQOL, and thus, aid surgical planning.

\section{Methods}

\section{Patient characteristics}

We retrospectively reviewed 220 patients who underwent surgery for degenerative spondylolisthesis from July 2003 to June 2008 at our institute. All patients were operated on by four senior surgeons (KES, WE, CSS and LJS). Eighteen of these patients were selected for this study by applying the following criteria: 1) one or twolevel degenerative lumbar spondylolisthesis; 2) treatment by posterior interbody fusion; 3 ) patients showing radiological solid fusion on follow up computed tomography (CT); and 4) a minimum clinical and radiologic followup of 24 months. The following exclusion criteria were applied: 1) more than three-level fusion; 2) a history of a previous spinal operation; and 3) the presence of severe systemic disease, a vertebral fracture, or osteoporosis. All patients visited our outpatient department in June 2010, and a trained nurse collected follow-up clinical data. The medical records of patients were reviewed, along radiographic studies that included preoperative and postoperative radiographs, computed tomography (CT) scans, and magnetic resonance images.

Average patient age was 60.8 years (48-72 years), and there were 8 men and 10 women. Mean symptom duration before surgery was 2.3 years (3 months - 10 years), and patients were observed for an average of 43.2 months (24-84 months). 14 patients underwent singlelevel fusions, of which 12 were at L4-L5 and 2 at L3-4. There were four two-level fusions, one at L4-L5-S1 and three at L3-L4-L5. Demographic data are summarized in table 1 . The study was authorized by the institutional review board of the Samsung medical center. Informed consent was obtained from all patients in accordance with the institutional review board at our institution.

\section{Clinical and radiological evaluations}

All patients were examined clinically and radiographically before and after surgery at the following times: immediately after surgery and at 3, 6, and 12 months and annually thereafter. At clinical evaluations, all patients completed the Visual Analogue Pain Score (VAS) for back pain and the Oswestry disability index (ODI) questionnaire in order to assess HRQOLs [12]. Clinical outcome was evaluated with improvement in VAS and in ODI. Preoperative and final follow up data were assessed using clinical charts and operative reports.

Sagittal alignments were evaluated preoperatively using 36-inch lateral films of the entire spine and both femoral heads. All films were obtained with the subject standing with arms crossed and knees fully extended with adequate lateral view of overlapping femoral heads and visualization from above the $C 7$ vertebral body to the sacral end plate. These full spine films were evaluated for spinopelvic sagittal parameters including sacral slope(SS), $\mathrm{PT}$, pelvic incidence (PI), sacrofemoral distance (SFD), and sacro-C7 plumb line distance (SC7D) (Figure 1). Other spinal parameters included in this analysis were thoracic kyphosis (TK) and lumbar lordosis (LL). The TK

Table 1 Summary of patient demographic and preoperative clinical characteristics

\begin{tabular}{ccc}
\hline Characteristic & \multicolumn{2}{c}{ Case } \\
\cline { 2 - 3 } & Group A (n= 10) & Group B (n = 8) \\
\hline Sex (M:F) & $3: 7$ & $5: 3$ \\
Mean age in yrs (range) & $61.0(48-72)$ & $60.5(48-69)$ \\
Spinal level & 1 & 1 \\
L3-4 & 7 & 5 \\
L4-5 & 2 & 1 \\
L3-4-5 & 0 & 1 \\
L4-5-S1 & & \\
\hline
\end{tabular}




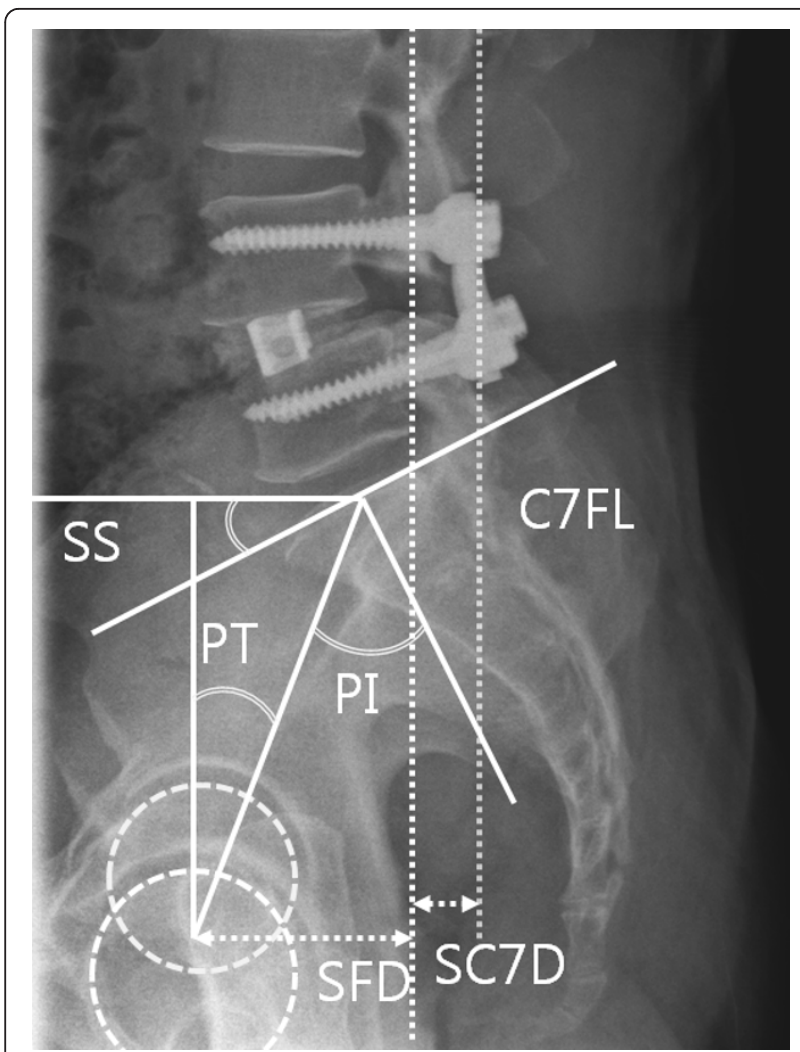

Figure 1 Illustration showing the pelvic parameters included in this analysis, that is, sacral slope (SS), pelvic tilt (PT), and pelvic incidence (PI). PI is a morphological parameter, whereas SS and PT are positional parameters. PI represents the algebraic sum of SS and PT, $(P I=S S+P T)$. SFD is the horizontal distance between the vertical bi-coxo-femoral axis and the vertical line passing through the posterior corner of the sacrum. The horizontal distance between C7 plumb line and the posterior corner of the sacrum (SC7D) was also measured. These two values were then used to calculate SC7D/ SFD ratio, which correspond to the ratio of SC7D to SFD.

was measured between the upper endplate of the most inclined vertebrae into the thoracolumbar junction zone and the superior plate of C7. The LL was measured using the Cobb method between the sacral plate and the upper endplate of the most inclined vertebrae into the thoracolumbar junction zone, corresponding to the inflection point where the spine transitions from lordosis to kyphosis. Each pre, postoperative and follow up measurement for radiologic parameter was performed twice by two observers, one medical student (KMK) and one neurosurgical -spine surgeon (LSH) who are independent from the operators.

Patients were divided into two groups using improvement of PT at last follow up: group A showed a tendency towards increased and unchanged PT; and group B showed a tendency towards decreased PT to normal range. Radiologic factors and clinical outcomes were compared statistically between two groups.

\section{Statistic analysis}

Statistical analysis was performed using PASW statistical software ver. 18.0 (SPSS Inc., Chicago, IL). The MannWhitney U-test was used to compare group clinical and radiological outcomes. Wilcoxon's rank sum test was used to compare differences between pre-, postoperative and final follow-up parameters of clinical and radiological outcomes. Correlation studies were performed using Pearson's coefficients to investigate relations between all radiologic parameters and VAS and ODI improvements.

\section{Results}

Ten patients were allocated to Group A (group of the increased and unchanged PT) and eight to Group B (group of the decreased PT). Table 1 summarizes the demographic characteristics. There were 10 females and 8 males. The patients' ages ranged from 48 to 72 years (mean, 60.8 years). The mean follow-up period was 43.1 months with a minimum period of 2 years (range 24-84 months). Table 2 shows clinical values and spinopelvic parameter of each group.

Most patients showed improvement of symptoms related to radiculopathy immediately after surgery. Mean VAS for all patients was 6.83 (range 9.03-4.63) before surgery and this improved after surgery to 2.50 (range $0.6-4.4$ ). The mean ODI was $46.4 \%$ (range 26.8$66 \%$ ) before surgery and this too improved after surgery to $21.5 \%$ (range $18.3-24.7 \%$ ). Mean VAS at last followup assessments were 3.20 in Group A and 1.63 in Group B; corresponding to a VAS improvement of $53.3 \%$ in Group A and of $76.1 \%$ in Group B. Mean ODI at last follow-up assessments were 43.2 in Group A and 50.4 in Group B; corresponding to an ODI improvement of $45.4 \%$ in Group A and of $61.7 \%$ in Group B. VAS and ODI improvements at follow-up were poorer in group A than in Group B (Table 3). Table 4 showed results of spinopelvic parameters in the two groups. No significant difference was found between preoperative and postoperative variables except PT in Group A. However, significant difference were found between the preoperative and postoperative values of PT, SS, TK, LL, and SFD/ SC7D in Group B. Between parameters of group A and $B$, significant difference were found on last follow up PT. Additionally there is borderline significance on preoperative PT, preoperative LL and last follow up SS.

Correlation analysis between all radiologic parameters of sagittal balance and VAS and ODI improvement in Groups A and B are presented in Table 5. VAS improvements in Group A were found to be significantly related to postoperative lumbar lordosis (Pearson's coefficient $=-0.829 ; \mathrm{p}=0.003)$. Similarly, ODI improvements were also found to be significantly associated with postoperative lumbar lordosis (Pearson's coefficient $=-0.700 ; \mathrm{p}=0.024)$. However, in Group B, 
Table 2 Result of clinical outcomes and spinopelvic parameter of 18 patients

\begin{tabular}{|c|c|c|c|c|c|c|c|c|c|c|c|c|c|c|c|c|c|c|c|}
\hline \multirow[t]{2}{*}{ case } & \multicolumn{2}{|c|}{ VAS } & \multicolumn{2}{|c|}{ ODI } & \multicolumn{3}{|c|}{ Pelvic tilt } & \multicolumn{3}{|c|}{ Sacral slope } & \multicolumn{3}{|c|}{ Pelvic incidence } & \multicolumn{3}{|c|}{ Lumbar lordosis } & \multicolumn{3}{|c|}{ SC7D/SFD } \\
\hline & preop & lastFU & preop & lastFU & preop & postop & lastFU & preop & postop & lastFU & preop & postop & lastFU & preop & postop & lastFU & preop & postop & LastFU \\
\hline A1 & 8 & 2 & 38 & 6 & 16 & 21 & 22 & 28 & 25.4 & 25.2 & 44 & 46.5 & 46.9 & 47 & 38.2 & 45.4 & -0.24 & 0.91 & 0.67 \\
\hline$A 2$ & 8 & 7 & 46 & 36 & 25.3 & 31.6 & 27.1 & 36.2 & 31.2 & 37.7 & 62.3 & 60.5 & 63.8 & 38.7 & 44.2 & 41.3 & 1.96 & 1.35 & 1.08 \\
\hline A3 & 8 & 2 & 36 & 28 & 30.7 & 26.3 & 30.4 & 17.8 & 21.3 & 21.5 & 47.6 & 49.2 & 50.9 & 38.1 & 45.5 & 46.1 & 0.97 & 0.76 & 0.52 \\
\hline A4 & 3 & 4 & 36 & 18 & 19.9 & 25.5 & 26.1 & 42.2 & 30.1 & 28.8 & 62.1 & 55.6 & 54.9 & 52.5 & 61.6 & 62 & 0.50 & 0.30 & 0.56 \\
\hline A5 & 7.5 & 3 & 46 & 50 & 25.3 & 34.2 & 38.7 & 19.6 & 13.3 & 11.2 & 44.9 & 47.5 & 49.9 & 41.6 & 47.2 & 52.6 & 0.99 & 0.82 & 0.98 \\
\hline A6 & 6 & 7 & 24 & 12 & 20.9 & 23.1 & 23.6 & 30.6 & 30.8 & 29.6 & 51.5 & 53.9 & 54.2 & 54.1 & 48.9 & 48.1 & 0.01 & 0.54 & 0.82 \\
\hline A7 & 10 & 0 & 60 & 12 & 15.1 & 21.4 & 17.7 & 26.6 & 18.5 & 23.1 & 41.7 & 39.9 & 40.8 & 34 & 29.7 & 32.7 & 0.60 & 0.68 & 0.32 \\
\hline A8 & 7 & 2 & 42 & 32 & 21.4 & 21.8 & 21.1 & 35.3 & 31.3 & 38.2 & 56.7 & 53.1 & 58.3 & 43.5 & 32 & 47.4 & 1.23 & 1.47 & 0.26 \\
\hline A9 & 9 & 1 & 86 & 16 & 24.3 & 20.5 & 26.2 & 31 & 33.2 & 27.3 & 55.3 & 53.7 & 55.5 & 50.4 & 45.6 & 36.4 & 2.23 & 1.16 & 0.76 \\
\hline A10 & 2 & 4 & 18 & 26 & 16.1 & 18 & 19.3 & 44.8 & 44.2 & 45.9 & 60.9 & 62.2 & 62.2 & 65.2 & 56.8 & 68.7 & -0.17 & 0.22 & -0.95 \\
\hline B1 & 8 & 2 & 44 & 12 & 23.9 & 22.5 & 20 & 40.7 & 43 & 46.3 & 64.6 & 65.5 & 66.3 & 51.6 & 58.1 & 55.6 & 0.92 & -0.32 & 0.20 \\
\hline B2 & 5 & 1 & 36 & 6 & 27.7 & 22.8 & 15.2 & 27.2 & 31.2 & 37.5 & 54.9 & 54 & 52.7 & 32.8 & 46.7 & 53.3 & 0.44 & 0.12 & -0.10 \\
\hline B3 & 10 & 2 & 74 & 16 & 25.1 & 30.7 & 20.3 & 29.8 & 24.3 & 34.7 & 54.9 & 55 & 55 & 42.7 & 40.8 & 51 & 0.69 & 0.60 & 0.50 \\
\hline B4 & 8 & 2 & 44 & 8 & 22.4 & 20.2 & 14.7 & 31.5 & 34 & 38 & 53.9 & 54.1 & 52.7 & 44.4 & 41.4 & 52.9 & 0.18 & -0.45 & -0.10 \\
\hline B5 & 7 & 2 & 36 & 23 & 20 & 17.5 & 14.5 & 24.1 & 21.2 & 26.2 & 44.1 & 38.7 & 40.7 & 24.7 & 20.8 & 33.3 & 1.09 & 0.19 & -0.25 \\
\hline B6 & 6.5 & 2 & 54 & 16 & 29.3 & 30.9 & 23.7 & 32.7 & 30.4 & 37.6 & 62 & 61.3 & 61.3 & 38.8 & 38.4 & 43.8 & 1.34 & 0.75 & 1.07 \\
\hline B7 & 5 & 1 & 88 & 50 & 31.2 & 26 & 22 & 20.2 & 26 & 30.1 & 51.4 & 52 & 52.1 & 37.8 & 31.7 & 41 & 0.29 & 0.27 & 0.29 \\
\hline B8 & 5 & 1 & 27 & 20 & 31.3 & 25.7 & 16.8 & 26.7 & 23.6 & 43 & 58 & 59.3 & 59.8 & 34.4 & 41.2 & 48.1 & 0.98 & -0.27 & 0.53 \\
\hline
\end{tabular}

SC7D = sacro-C7 plume line distance; SFD = sacro-femoral distance. 
Table 3 Comparison of clinical outcomes in the two study groups based on changes in pelvic tilt after spinal fusion

\begin{tabular}{|c|c|c|c|c|c|c|}
\hline \multirow[t]{2}{*}{ Group } & \multicolumn{2}{|c|}{ VAS } & \multirow[t]{2}{*}{ Improvement rate of VAS } & \multicolumn{2}{|c|}{ ODI } & \multirow[t]{2}{*}{ Improvement rate of OD } \\
\hline & Preoperative & Last FU & & Preoperative & Last FU & \\
\hline$A(n=10)$ & $6.85 \pm 2.53$ & $3.20 \pm 2.35$ & $53.3 \%^{\dagger}$ & $43.2 \pm 19.0$ & $23.6 \pm 13.4$ & $45.4 \%^{\dagger}$ \\
\hline$B(n=8)$ & $6.81 \pm 1.81$ & $1.63 \pm 0.52$ & $76.1 \%^{\dagger}$ & $50.4 \pm 20.8$ & $18.9 \pm 13.8$ & $61.7 \%^{\dagger}$ \\
\hline$P$ value* & ns & $<0.05$ & $<0.05$ & ns & $<0.05$ & $<0.05$ \\
\hline
\end{tabular}

* Statistical significance of value between group A and B was determined using Mann-Whitney $U$ test.

$\dagger p<0.05$; Statistical significance of value between preoperative and last follow up was determined using Wilcoxon's signed rank test.

Values are presented as means \pm standard deviations.

VAS and ODI improvements were not found to be related to postoperative lumbar lordosis and to spinopelvic parameters.

\section{Discussion}

The optimal surgical approach to the management of lumbar degenerative spondylolisthesis has yet to be determined. Although gross spinal imbalance in association with degenerative lumbar spondylolisthesis is rare, more subtle forms of segmental imbalance may influence early surgical outcome and the later development of adjacent segment disease $[3,13,14]$. Furthermore, although slippage and lordosis at the level of spondylolisthesis have been evaluated radiologically, few reports have discussed lumbar sagittal balance in patients with degenerative lumbar spondylolisthesis

In an early study on 95 patients, Schwab et al identified radiologic parameters correlated with self-perceived pain (measured using a VAS scale), namely, intervertebral subluxation (olisthesis), L3 and L4 coronal vertebral obliquity, and loss of lumbar lordosis [15]. In addition, in a later report, loss of lordosis was also found to be correlated with lower Short Form 36 (SF-36) scores [16]. More recently, Glassman et al investigated the relationship between global alignment and measures of HRQOL, and found that sagittal vertical axis (measured as the offset between $\mathrm{C} 7$ plumb line and the posterosuperior corner of S1) was correlated with pain and a decrease in function as measured using ODI and SF-12 $[3,4]$. Considerable work is now directed at improving our understanding of not only ideal spinal alignment but also of spinopelvic relationships. Lazennec et al found that PT was correlated with increased pain in patients that underwent a lumbosacral fusion and demonstrated that patients with a larger postoperative PT were more likely to demonstrate residual pain [17].

\section{Clinical and radiological outcomes based on postoperative PT}

We noted that a change of pelvic tilt after spinal fusion was associated with improvements in VAS and ODI, and a statistically significant association was observed

Table 4 Mean values ( \pm standard deviation) of Spinopelvic parameters in the two study groups based on changes in pelvic tilt after spinal fusion

\begin{tabular}{|c|c|c|c|c|c|c|c|c|c|}
\hline \multirow{2}{*}{$\begin{array}{c}\text { Variable } \\
\text { (normal range*) } \\
\text { Group }\end{array}$} & \multicolumn{3}{|c|}{$\begin{array}{l}\text { Pelvic tilt }\left({ }^{\circ}\right) \\
(12-18)\end{array}$} & \multicolumn{3}{|c|}{$\begin{array}{c}\text { Sacral slope }\left(^{\circ}\right) \\
(36-42)\end{array}$} & \multicolumn{3}{|c|}{$\begin{array}{l}\text { Pelvic incidence }\left({ }^{\circ}\right) \\
(48-55)\end{array}$} \\
\hline & Preop & Postop & Last FU & Preop & Postop & Last FU & Preop & Postop & Last FU \\
\hline $\begin{array}{c}A \\
(n=10)\end{array}$ & $21.5 \pm 5.0$ & $24.3 \pm 5.1$ & $25.1 \pm 6.2^{\dagger}$ & $31.2 \pm 8.8$ & $27.9 \pm 8.7$ & $28.9 \pm 9.8$ & $52.7 \pm 7.9$ & $52.2 \pm 6.7$ & $53.7 \pm 7.0$ \\
\hline $\begin{array}{c}B \\
(n=8)\end{array}$ & $26.4 \pm 4.2$ & $24.5 \pm 4.7$ & $18.4 \pm 3.6^{\dagger}$ & $29.1 \pm 62$ & $29.2 \pm 7.1$ & $36.7 \pm 6.5^{\dagger}$ & $55.5 \pm 6.3$ & $55.0 \pm 8.0$ & $55.1 \pm 7.7$ \\
\hline$p$ valuef & 0.06 & ns & 0.01 & ns & ns & 0.09 & ns & ns & ns \\
\hline $\begin{array}{c}\text { Variable } \\
\text { (normal range*) }\end{array}$ & \multicolumn{3}{|c|}{$\begin{array}{c}\text { Thoracic kyphosis }\left({ }^{\circ}\right) \\
(41-48)\end{array}$} & \multicolumn{3}{|c|}{$\begin{array}{c}\text { Lumbar lordosis }\left({ }^{\circ}\right) \\
(43-61)\end{array}$} & \multicolumn{3}{|c|}{$\begin{array}{l}\text { SC7D/SFD } \\
(-1.9-0.1)\end{array}$} \\
\hline Group & Preop & Postop & Last FU & Preop & Postop & Last FU & Preop & Postop & Last FU \\
\hline $\begin{array}{c}\text { A } \\
(n=10)\end{array}$ & $38.4 \pm 9.7$ & $36.4 \pm 8.8$ & $33.7 \pm 10.0$ & $46.5 \pm 9.3$ & $45.0 \pm 9.9$ & $48.1 \pm 10.9$ & $0.81 \pm 0.9$ & $0.82 \pm 0.4$ & $0.50 \pm 0.6$ \\
\hline $\begin{array}{c}B \\
(n=8)\end{array}$ & $35.2 \pm 8.9$ & $37.1 \pm 8.9$ & $41.3 \pm 9.6^{\dagger}$ & $38.4 \pm 8.1$ & $39.9 \pm 10.8$ & $47.4 \pm 7.5^{\dagger}$ & $0.74 \pm 0.4$ & $0.11 \pm 0.4$ & $0.27 \pm 0.4^{\dagger}$ \\
\hline$p$ value $\neq$ & ns & ns & ns & 0.09 & ns & ns & ns & 0.04 & ns \\
\hline
\end{tabular}

SC7D = sacro-C7 plume line distance; SFD = sacro-femoral distance.

*Values are means from studies that included adult subjects aged 20 to 85 years without any symptom or history suggestive of spinal disease [5,7,22-33].

$\mathrm{tp}<0.05$; Statistical significance of value between preoperative and last follow up was determined using Wilcoxon's signed rank test.

$\neq \mathrm{p}<0.05$; Statistical significance of value between group A and B was determined using Mann-Whitney U test. 
Table 5 Pearson's correlation coefficients between spinopelvic and clinical parameters in the two study groups

\begin{tabular}{ccccc}
\hline Parameter & \multicolumn{2}{c}{$\begin{array}{c}\text { Group A } \\
(\mathbf{n}=10)\end{array}$} & \multicolumn{2}{c}{$\begin{array}{c}\text { Group B } \\
(\mathbf{n}=\mathbf{8})\end{array}$} \\
\cline { 2 - 5 } & $\Delta$ VAS & $\Delta$ ODI & $\Delta$ VAS & $\Delta$ ODI \\
\hline Sacral slope $\left(^{\circ}\right)$ & -0.612 & -0.327 & 0.128 & 0.281 \\
Pelvic incidence $\left(^{\circ}\right)$ & -0.621 & -0.560 & 0.051 & 0.270 \\
Thoracic kyphosis $\left({ }^{\circ}\right)$ & -0.096 & -0.265 & 0.105 & 0.251 \\
Lumbar lordosis $\left({ }^{\circ}\right)$ & $-0.829^{\dagger}$ & $-0.700^{*}$ & 0.394 & 0.675 \\
SC7D/SFD & 0.519 & 0.493 & -0.152 & -0.025 \\
\hline
\end{tabular}

$\mathrm{SC7D}=$ sacro-C7 plume line distance; SFD = sacro-femoral distance. $\triangle \mathrm{VAS}=$ Improvement rate between preoperative VAS and Last follow up VAS; $\triangle \mathrm{ODI}=\mathrm{Improvement}$ rate between preoperative ODI and Last follow up ODI. ${ }^{*} \mathrm{P}<0.05$, or $\mathrm{P} \mathrm{P}<0.01$.

between lumbar lordosis and improvements in VAS and ODI in patients whose postoperative pelvic tilt was not improved. By classifying patients according to an in improvement in pelvic tilt after operation demonstrated that pain and disability were greater in Group A than in Group B. Furthermore, patients in Group A had higher levels of self-reported pain and disability. In other words, patients with a non-improved PT postoperatively also had lower HRQOLs. In Group A, patients showed a tendency toward a poor clinical outcome. However, interestingly patients who presented with lower LL showed a better clinical outcome, and patients without lower LL in Group A experienced the highest levels of self reported pain and disability. On the other hand, in Group B, patients had better clinical outcomes regardless of LL values and the other parameters.

Actually, it would seem that there is the morphological difference between both groups preoperatively although this difference is not significant statistically. In group B with lumbar hypolordosis, operation could improve the lumbar lordosis into normal range by compression following decreasing PT. In group A with well compensated spondylolisthesis showing normal lumbar lordosis, however, operation could not improve any spinopelvic parameter including lumbar lordosis and pelvic tilt. Finally, the surgical result of group with lumbar hypolordosis was better than those of group with normal lumbar lordosis.

\section{Importance of PT and lumbar lordosis}

Improvements in PT postoperatively played a significant role in the achievement of a good clinical outcome, as determined by VAS and ODI. Although postoperative PT was not improved, LL also contributed to a good clinical outcome. It is becoming increasingly recognized that studies of spinal alignment should include pelvic position. Although PI determines LL, PT is a positional parameter that reflects compensation to spinal deformity. This study confirms that pelvic position, as measured by PT, is correlated with HRQOL in the setting of adult deformity, and that high PT values reflect compensatory pelvic retroversion due to sagittal spinal malalignment. Furthermore, the significant correlation found between postoperative PT improvement and clinical outcome appears to indicate that resetting PT to a normal value is important for restoring ambulatory function by improving the range of hip extension.

However, Increasing PT is not the only way to compensate a local loss of lordosis. The primary compensation is obtained by hyper extension of the segment above or below the hypolordosis area. This study also confirms the presence of relationships between LL and clinical outcomes, which is consistent with published reports $[18,19]$. LL is a key consideration when analyzing radiographic alignment, and is thought to cause chronic lower back pain by increasing traction loadings on posterior elements of the spine, including the paravertebral muscles [20].

Therefore, obtaining lordosis at fused segments may be useful for controlling lower back pain. In case of a hypolordotic fusion, there is a painful compensation in hyper extension at the upper level. The global LL does not change but the patient is not improved. PT remains slightly impaired, but the pain is due to the hyper extension compensation (Figure 2). Such residual lower back pain may result from postoperative change of the zygapophysial joint, the paravertebral muscle, the posterior ligamentous complex and the adjacent segment change.

\section{Other Radiographic Parameters of Importance}

The issue of spinal balance is attracting attention in the literature. However, conflicting results have been reported about the relationship between radiological factors related to sagittal balance and clinical outcomes after lumbar arthrodesis $[10,21]$. With regard to early clinical outcomes, Kawakami et al. noted improved clinical recovery rates in patients that underwent fusion for degenerative spondylolisthesis when the L1 axis S1 interval (their measure of the position of the plumb line in front of the sacrum) was less than $35 \mathrm{~mm}$ and when lordosis of the fused segments was achieved [10]. However, although the correction of sagittal plane deformity may be achieved by a number of means, there appears to be relatively little information in the literature regarding degenerative spondylolisthesis. In the present study, no significant relationship was found between radiological factors related to sagittal balance and clinical success except PT and LL.

\section{Conclusion}

This is the first study to evaluate the impact of sagittal balance in patients with degenerative spondylolisthesis that underwent fusion surgery. Thus, clinically, analyses 


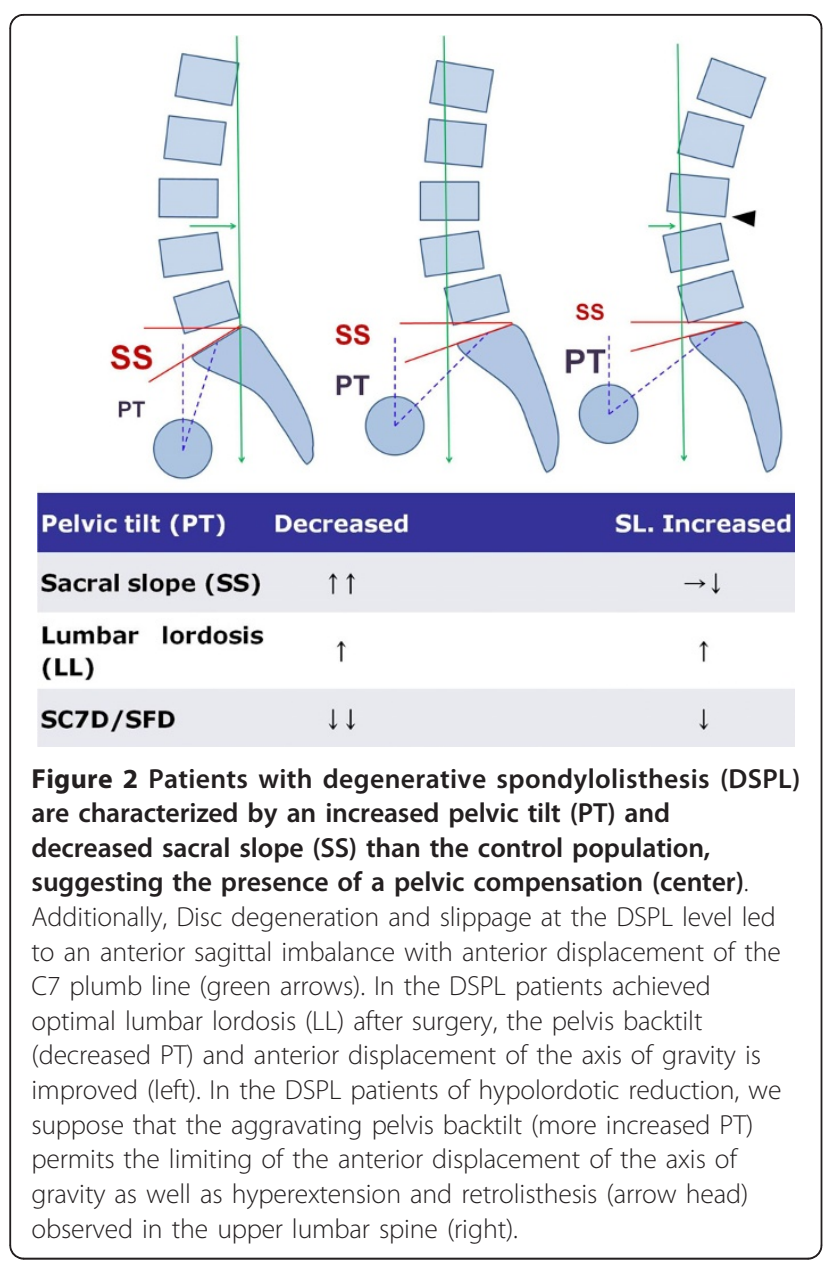

of spinopelvic parameters, such as, pelvic tilt and lumbar lordosis, appear to be essential to the understanding of the impact of spinal deformity and the treatment choice in degenerative lumbar spondylolisthesis. Nevertheless, the retrospective study design of the present study and the small number of patients included should be considered when interpreting our results.

\section{Acknowledgements}

The authors wish to thank Dr. John Roberts for editing the manuscript and help with the English language.

\section{Author details}

'Department of Neurosurgery, Spine center, Samsung Medical Center, Sungkyunkwan University, School of Medicine, Seoul, 135-710, Republic of Korea. ${ }^{2}$ School of Medicine, Konkuk University Seoul, 143-701, Republic of Korea. ${ }^{3}$ Department of Orthopedic Surgery, Spine center, Samsung Medical Center, Sungkyunkwan University, School of Medicine, Seoul, 135-710, Republic of Korea.

\section{Authors' contributions}

MKK collected data and drafted the manuscript. SHL has made substantial contributions to conception, design, data collection and revised it critically for important intellectual content. ESK, WE, SSC participated in analysis and interpretation of data, CSL participated in its design. All authors gave final approval of the version to be published.

\section{Competing interests}

The authors declare that they have no competing interests.

Received: 28 September 2010 Accepted: 5 April 2011

Published: 5 April 2011

\section{References}

1. Kumar MN, Baklanov A, Chopin D: Correlation between sagittal plane changes and adjacent segment degeneration following lumbar spine fusion. Eur Spine J 2001, 10:314-319.

2. Gottfried ON, Daubs MD, Patel AA, Dailey AT, Brodke DS: Spinopelvic parameters in postfusion flatback deformity patients. Spine J 2009, 9:639-647.

3. Glassman SD, Berven S, Bridwell K, Horton W, Dimar JR: Correlation of radiographic parameters and clinical symptoms in adult scoliosis. Spine (Phila Pa 1976) 2005, 30:682-688.

4. Glassman SD, Bridwell K, Dimar JR, Horton W, Berven S, Schwab F: The impact of positive sagittal balance in adult spinal deformity. Spine (Phila Pa 1976) 2005, 30:2024-2029.

5. Mac-Thiong JM, Transfeldt EE, Mehbod AA, Perra JH, Denis F, Garvey TA, Lonstein JE, Wu C, Dorman CW, Winter RB: Can C7 plumbline and gravity line predict health related quality of life in adult scoliosis? Spine (Phila Pa 1976) 2009, 34:E519-27.

6. Hanson DS, Bridwell KH, Rhee JM, Lenke LG: Correlation of pelvic incidence with low- and high-grade isthmic spondylolisthesis. Spine (Phila Pa 1976) 2002, 27:2026-2029.

7. Labelle H, Roussouly P, Berthonnaud E, Transfeldt E, O'Brien M, Chopin D, Hresko T, Dimnet J: Spondylolisthesis, pelvic incidence, and spinopelvic balance: a correlation study. Spine (Phila Pa 1976) 2004, 29:2049-2054.

8. Labelle H, Roussouly P, Chopin D, Berthonnaud E, Hresko T, O'Brien M: Spino-pelvic alignment after surgical correction for developmental spondylolisthesis. Eur Spine J 2008, 17:1170-1176.

9. Barrey C, Jund J, Perrin G, Roussouly P: Spinopelvic alignment of patients with degenerative spondylolisthesis. Neurosurgery 2007, 61:981-986.

10. Kawakami M, Tamaki T, Ando M, Yamada H, Hashizume H, Yoshida M: Lumbar sagittal balance influences the clinical outcome after decompression and posterolateral spinal fusion for degenerative lumbar spondylolisthesis. Spine (Phila Pa 1976) 2002, 27:59-64.

11. Korovessis P, Repantis T, Papazisis Z, lliopoulos P: Effect of sagittal spinal balance, levels of posterior instrumentation, and length of follow-up on low back pain in patients undergoing posterior decompression and instrumented fusion for degenerative lumbar spine disease: a multifactorial analysis. Spine (Phila Pa 1976) 2010, 35:898-905.

12. Fairbank JC, Couper J, Davies JB, O'Brien JP: The Oswestry low back pain disability questionnaire. Physiotherapy 1980, 66:271-273.

13. Kuntz C, Levin LS, Ondra SL, Shaffrey Cl, Morgan CJ: Neutral upright sagittal spinal alignment from the occiput to the pelvis in asymptomatic adults: a review and resynthesis of the literature. J Neurosurg Spine 2007, 6:104-112.

14. Roussouly P, Gollogly S, Noseda O, Berthonnaud E, Dimnet J: The vertical projection of the sum of the ground reactive forces of a standing patient is not the same as the $\mathrm{C} 7$ plumb line: a radiographic study of the sagittal alignment of 153 asymptomatic volunteers. Spine (Phila Pa 1976) 2006, 31:E320-325.

15. Schwab FJ, Smith VA, Biserni M, Gamez L, Farcy JP, Pagala M: Adult scoliosis: a quantitative radiographic and clinical analysis. Spine (Phila Pa 1976) 2002, 7:387-392.

16. Schwab F, Dubey A, Pagala M, Gamez L, Farcy JP: Adult scoliosis: a health assessment analysis by SF-36. Spine (Phila Pa 1976) 2003, 28:602-626.

17. Lazennec JY, Ramare S, Arafati N, Laudet CG, Gorin M, Roger B, Hansen S, Saillant G, Maurs L, Trabelsi R: Sagittal alignment in lumbosacral fusion: relations between radiological parameters and pain. Eur Spine J 2000, 9:47-55.

18. Schwab F, Farcy JP, Bridwell K, Berven S, Glassman S, Harrast J, Horton W: A clinical impact classification of scoliosis in the adult. Spine (Phila Pa 1976) 2006, 31:2109-2114.

19. Jang JS, Lee SH, Kim JM, Min JH, Han KM, Maeng DH: Can patients with sagittally well compensated lumbar degenerative kyphosis benefit from surgical treatment for intractable back pain? Neurosurgery 2009, 64:115-21, discussion 121. 
20. Kamo Y, Takemitsu Y: Diagnosis for Osteoporosis 3: Present history and physical examination [in Japanese]. Seikei Geka 1992, 43:1111-18.

21. Goldstein JA, Macenski MJ, Griffith SL, McAfee PC: Lumbar sagittal alignment after fusion with a threaded interbody cage. Spine (Phila Pa 1976) 2001, 26:1137-1142.

22. Potter BK, Lenke LG, Kuklo TR: Prevention and management of iatrogenic flatback deformity. J Bone Joint Surg Am 2004, 86-A:1793-808.

23. Saha D, Gard S, Fatone S, Ondra S: The effect of trunk-flexed postures on balance and metabolic energy expenditure during standing. Spine (Phila Pa 1976) 2007, 32:1605-1611.

24. Lu DC, Chou D: Flatback syndrome. Neurosurg Clin N Am 2007, 18:289-294.

25. Bridwell K: Causes of sagittal spinal imbalance and assessment of the extent of needed correction. Instr Course Lect 2006, 55:567-575.

26. Labelle H, Roussouly P, Berthonnaud E, Dimnet J, O'Brien M: The importance of spino-pelvic balance in L5-s1 developmental spondylolisthesis: a review of pertinent radiologic measurements. Spine (Phila Pa 1976) 2005, 30:527-34.

27. Rajnics $P$, Templier A, Skalli W, Lavaste F, Illes T: The association of sagittal spinal and pelvic parameters in asymptomatic persons and patients with isthmic spondylolisthesis. J Spinal Disord Tech 2002, 15:24-30.

28. Meyers LL, Dobson SR, Wiegand D, Webb JD, Mencio GA: Mechanical instability as a cause of gait disturbance in high-grade spondylolisthesis: a pre- and postoperative three-dimensional gait analysis. $J$ Pediatr Orthop 1999, 19:672-676.

29. Vaz G, Roussouly P, Berthonnaud E, Dimnet J: Sagittal morphology and equilibrium of pelvis and spine. Eur Spine J 2002, 11:80-87.

30. Vialle R, Iharreborde B, Dauzac C, Guigui P: Intra and inter-observer reliability of determining degree of pelvic incidence in high-grade spondylolisthesis using a computer assisted method. Eur Spine J 2006 15:1449-1453.

31. Islam NC, Wood KB, Transfeldt EE, Winter RB, Denis F, Lonstein JE, Ogilvie JW: Extension of fusions to the pelvis in idiopathic scoliosis. Spine (Phila Pa 1976) 2001, 26:166-173.

32. Park JY, Cho YE, Kuh SU, Cho JH, Chin DK, Jin BH, Kim KS: New prognostic factors for adjacent segment degeneration after one-stage 360 degrees fixation for spondylolytic spondylolisthesis: special reference to the usefulness of pelvic incidence angle. J Neurosurg Spine 2007, 7:139-144

33. O'Brien MF, Kuklo TR, Blanke KM, Lenke LG: Spinal Deformity Study Group. Radiographic Measurement Manual. Memphis, TN: Medtronic Sofamor Danek; 2004.

\section{Pre-publication history}

The pre-publication history for this paper can be accessed here: http://www.biomedcentral.com/1471-2474/12/69/prepub

\section{doi:10.1186/1471-2474-12-69}

Cite this article as: Kim et al: The impact of sagittal balance on clinical results after posterior interbody fusion for patients with degenerative spondylolisthesis: A Pilot study. BMC Musculoskeletal Disorders 2011 12:69. 